\title{
Unexpected chalcogen bonds in tetravalent sulfur compounds
}

Received 00th January 20xx, Accepted 00th January 20xx DOI: $10.1039 / \times 0 \times x 00000 x$

\author{
Antonio Franconetti, ${ }^{a}$ David Quiñonero, ${ }^{a}$ Antonio Frontera*a ${ }^{a}$ and Giuseppe Resnati*b
}

In this manuscript we have combined a CSD (Cambridge Structural Database) analysis with theoretical calculations (RIMP2/def2-TZVP level of theory) to study the importance of polarizability in chalcogen bonding interactions. It is well known that chalcogen bonds are stronger for less electronegative chalcogen atoms, i.e. $\mathrm{S}<\mathrm{Se}<\mathrm{Te}$ and in the presence of electron-withdrawing substituents at the chalcogen. Herein, we report experimental and theoretical evidence (RIMP2/def2-TZVP) that the chalcogen bond acceptor (Lewis base) has preference in some cases for the $\sigma$-hole that is opposite to the more polarizable group instead of the more electron withdrawing one, as confirmed by Natural Bond Orbital (NBO) and the Bader's theory of "atoms-in-molecules" computational tools.

\section{Introduction}

The understanding of noncovalent interactions is vital to keep progressing in many areas, especially supramolecular chemistry, crystal engineering, and materials science. ${ }^{1-3}$ These areas usually rely on traditional hydrogen bonding ${ }^{4-7}$ and, more recently, halogen bonding (XB) interactions. ${ }^{8}$ During the last decade also other noncovalent $\sigma / \pi$-hole interactions involving $p$-block elements have accomplished a captivating progress $^{9-25}$ and in this field chalcogen bonding (ChB) has been receiving the greatest attention. $\mathrm{ChB}$ is the interaction of the $\sigma$-hole family wherein an electron donor attractively interacts with an electrophilic region of a group 16 element (typically $S$, Se, Te). ${ }^{26-28}$ The strength and directionality of $\mathrm{ChB}$ is comparable to $\mathrm{XB}^{29-31}$ Distinctive features of $\sigma$-hole interactions involving Groups 17 and 16 elements with respect to hydrogen bonds are the greater hydrophobicity and directionality. These characteristics have been recently used to design high-precision catalysts that function in apolar media. For instance, benzodiselenazoles have been used for $\mathrm{ChB}$ based catalysis that takes advantage of $\sigma$-holes on conformationally rigid selenium atoms pointing to the same region (active catalytic site). ${ }^{32-35}$ Moreover, Beer and coworkers have used rotaxane-based receptors containing tellurium that are able to recognize anions efficiently. ${ }^{36}$

The most studied ChBs are those of divalent $\mathrm{S}$ or Se derivatives that engage in noncovalent interactions with lone pair donor atoms atom like $\mathrm{N}$ or $\mathrm{O}^{37-39}$ The strength of this type of $\mathrm{ChBs}$ is comparable to (sometimes stronger than) that of $\mathrm{HBs} .{ }^{40}$ But the $S$ atom frequently engages in higher order bonding, as, for example, the tetravalent $\mathrm{S}$ in $\mathrm{SF}_{4}$. As a matter of fact, strong

\footnotetext{
Department of Chemistry, Universitat de les Illes Balears, Crta. de Valldemossa km 7.5, 07122 Palma (Baleares), Spain. E-mail: toni.frontera@uib.es

b. Laboratory of Nanostructured Fluorinated Materials (NFMLab). Department of Chemistry. Materials and Chemical Engineering "Giulio Natta", Politecnico di Milano, Via L. Mancinelli 7, 20131 Milano, Italy. E-mail: giuseppe.resnati@polimi.it

Electronic Supplementary Information (ESI) available: Cartesian coordinates of the optimized complexes. See DOI: 10.1039/x0xx00000x
}

ChBs between $\mathrm{SF}_{4}$ and amines have been reported, up to 14 $\mathrm{kcal} / \mathrm{mol}$ for trimethylamine. ${ }^{41}$ As detailed in Fig. $1 \mathrm{a}$, the $\mathrm{SF}_{4}$ has two symmetrically located $\sigma$-holes $(+36 \mathrm{kcal} / \mathrm{mol}$ at the M06/6-31+G* level of theory) which are adequate for interacting with Lewis bases. The $\mathrm{X}$-ray characterization of highly directional $1: 1$ adducts between $\mathrm{SF}_{4}$ and pyridine (Fig. 1b), triethylamine (Fig. 1c) and cyclopentanone (Fig. 1d) provide strong experimental support to $\mathrm{ChB}$ in hypervalent sulfur derivatives. ${ }^{41 \mathrm{~b}}$ The $\mathrm{S} \cdots \mathrm{N}$ distance is shorter in the triethylamine adduct, consistent with its stronger basicity. It is also interesting to mention the X-ray co-crystal structures of $\mathrm{SF}_{4}$ adducts with cyclopentanone, tetrahydrofurane, and dimethoxyethane where two highly directional ChBs are formed (they are $174^{\circ}$ and $176^{\circ}$ in the cyclopentanone complex). ${ }^{41 \mathrm{~d}}$ In all cases $\mathrm{SF}_{4}$ adopts the seesaw conformation and the electron rich atom sits precisely opposite to one of the two equatorial $\mathrm{F}$ atoms of $\mathrm{SF}_{4}$.

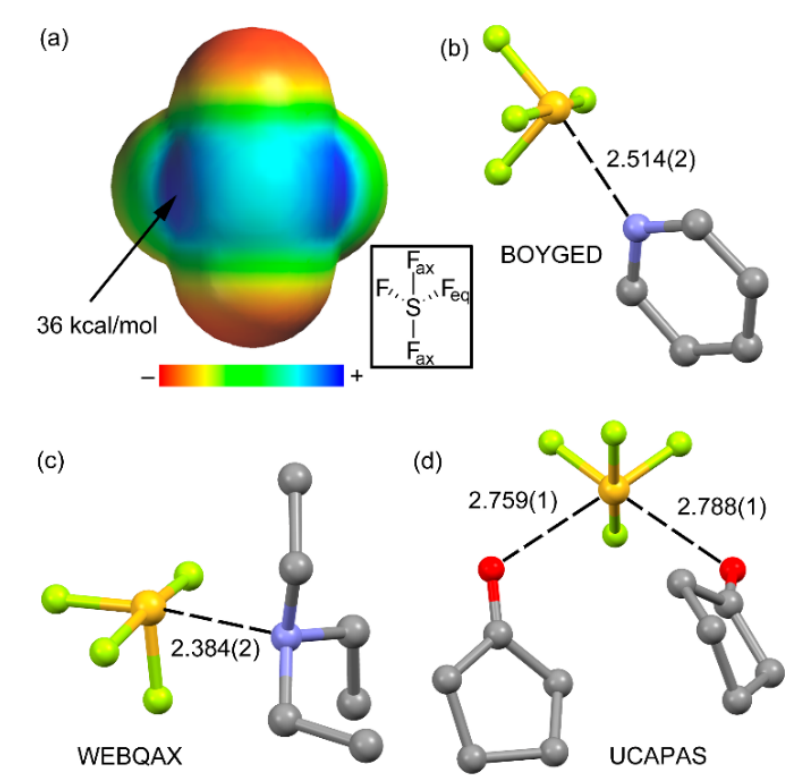


Fig. 1 (a) MEP (Molecular Electrostatic Potential) surface (0.001 a.u.) of $\mathrm{SF}_{4}$. (b,c) X-ray solid state structures of $\mathrm{SF}_{4}$ adducts with pyridine (BOYGED) and triethylamine (WEBQAX). (d) X-ray co-crystal structure of $\mathrm{SF}_{4}$ and cyclopentanone (UCAPAS). Distances in $\AA$

Similar to pnictogen bonding and ChBs formed by trivalent and divalent atoms, respctively, ${ }^{41 e} \mathrm{ChBs}$ formed by hypervalent sulfur are strongly affected by steric effects. To this respect, Scheiner and Lu have recently reported an interesting study dealing with the issue of steric crowding in hypervalent halogen, chalcogen and pnicogen atoms in the context of noncovalent bonds. ${ }^{42}$ The effect is not limited to the issue of steric repulsions of the substituents with the electron donor molecule. The substituents also influence the position and intensity of any $\sigma$-holes and provoke a certain degree of geometrical deformation occurring when the Lewis acid and base approach one another. In this manuscript we deal with another aspect of the substituents effects on $\sigma$-hole interactions. It is usually assumed for $\sigma$-hole interactions ( $X-$ D $\cdots: A)$ that their strength depends on two factors: a $\sigma$-hole becomes more positive when $D$ is more polarizable (heavier atoms) and when $X$ is more electron withdrawing. Herein we show that the polarizability of $X$ is also an important aspect that it is usually not considered. We provide theoretical and experimental indications (retrieved from the Cambridge Structural Database, CSD) that ChBs involving hypervalent chalcogens may be located preferentially opposite to the more polarizable substituent instead of the more electron withdrawing one.

\section{Results and discussion}

\section{Preliminary CSD search}

An inspection of the CSD (Conquest 1.23) reveals seventeen Xray structures containing the $\mathrm{SF}_{4}$ unit and all of them are multicomponent crystals wherein sulfur exhibits one or two ChBs (Table 1). Other twelve structures contain the moiety $S R R^{\prime} F_{2} \quad\left(R, R^{\prime}=\right.$ organic fragment); in all these systems substituents at sulfur adopt a seesaw conformation with the two $\mathrm{F}$ atoms in the axial positions. In nine of these structures $\mathrm{R}$ $=R^{\prime}$ and as these residues form two identical $\sigma$-holes at sulfur, these structures are not useful to analyze a possible competition between the two ChBs involving these holes. Finally, the search reveals only two different compounds containing the $\mathrm{SRF}_{3}$ moiety, i.e. XEKYOD(01) and CUVSOB. However only the former is particularly adequate for analyzing the ability of two different $\sigma$-holes (one opposite to the electron withdrawing $F$ atom and the other opposite to $R$ ) to interact with electron rich sites. The CUVSOB structure is not adequate to study the competition between the two $\sigma$-holes because the two intramolecular chalcogen bonding are necessarily opposite to the F-atom due to the $(E)$ geometry of the carbon-carbon double bond, namely of the relative arrangement of the involved $-\mathrm{CF}_{3}$ and $-\mathrm{SF}_{3}$ groups (see Fig. $2 a)$. There are three CSD structures containing the $S R R^{\prime} F_{2}(R \neq$ $R^{\prime}$ ) fragment, which are in principle adequate for analyzing the competition of both $\sigma$-holes. However, in one of them (refcode
QAKWAA, see Fig. 2b) the SRR' $F_{2}$ fragment is an anion and, no surprise, it does not function as chalcogen bond donor. Therefore, only EHAWAL and HIJFEL in addition to XEKYOD refcodes are commented below.

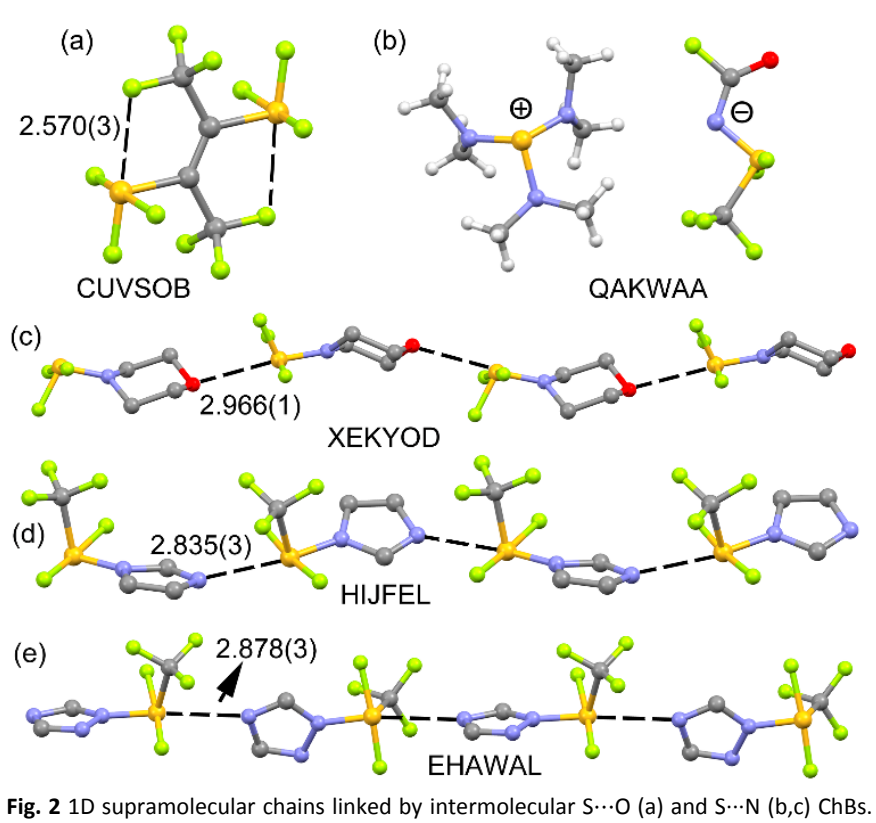
Distances in $\AA$.

In Fig. 2c-e we show the three unique examples retrieved from the CSD that are adequate to analyze the competition between both $\sigma$-holes. The refcode XEKYOD ( $\mathrm{RSF}_{3}$ family) is morpholinosulfur trifluoride, a well-known fluorinating agent endowed with a thermal stability $^{43}$ higher than the diethylamino analogue (diethylaminosulfur trifluoride, DAST) ${ }^{44}$ that has the potential to decompose violently. In the solid state (see Fig. 2c) each morpholine- $\mathrm{SF}_{3}$ adduct establishes a $\mathrm{S} \cdots \mathrm{O} \mathrm{ChB}$ with a nearby adduct and the interaction governs the formation of an infinite 1D supramolecular chain. The equatorial lone pair (LP) of the O-atom of the morpholine ring approaches sulfur on the extension of the $\mathrm{N}-\mathrm{S}$ bond (instead of the $\mathrm{F}-\mathrm{S}$ bond); namely, the $\mathrm{ChB}$ is not established with the $\sigma$-hole that is opposite to the more electronegative $\mathrm{F}$ atom. An analogous behavior is observed in HIJFEL and EHAWAL X-ray structures (Fig. 2b,c). The $\mathrm{CF}_{3}$ group is even more electron withdrawing than an F-atom, but in both these structures infinite 1D supramolecular chains are formed in the solid state where the $\mathrm{S} \cdots \mathrm{N}$ ChBs are established opposite to the $\mathrm{N}-\mathrm{S}$ bonds instead of the $\mathrm{CF}_{3}-\mathrm{S}$ bonds. 
Table 1. CSD reference codes for tetravalent $\mathrm{SF}_{4}$ cocrystals, $\mathrm{SRR}_{2} \mathrm{~F}_{2}$ (in parenthesis those with $R \neq R^{\prime}$ )and $S R F_{3}$ (in italics) $X$-ray structures

\begin{tabular}{cccc}
\hline & \multirow{2}{*}{$\mathrm{SF}_{4}$ adducts } & \multicolumn{2}{c}{$\mathrm{SRR}^{\prime} \mathrm{F}_{2} \& \mathrm{SRF}_{3}$ adducts } \\
\hline OTIRAM & BOYGIH & (EHAWAL) & XARFEB \\
OTIREQ & BOYGON & MAFSUL & XARFAX \\
OTIRIU & UCANOE & MAFSUL01 & XARFAX01 \\
OTISAN & UCANUK & KIMMUO & \\
OTISER & UCAPAS & EHAVUE & \\
OTISOB & UCAPEW & (HIJFEL) & CUVSOB \\
OTIROA & UCAPIA & QAHTEY & XEKYOD \\
BIBRUB & WEBQAX & QAHTIC & XEKYODO1 \\
BOYGED & & (QAKWAA) &
\end{tabular}

\section{Theoretical study}

For the theoretical study, we have considered three $\mathrm{SRF}_{3}$ molecules wherein $\mathrm{R}$ groups have different properties (Scheme 1). In compound $\mathbf{1} R$ is the $N$-morpholino residue and in compounds $\mathbf{2}$ and $\mathbf{3}$ it is a phenyl and a 2-isoindolyl group, respectively. These three $\mathrm{R}$ moieties allow to explore the effect on the $\sigma$-holes at sulfur of pendants possessing quite different degrees of polarizability and resulting in different types of bonds to S-atom (i.e., $\mathrm{C}-\mathrm{S}$ and $\mathrm{N}-\mathrm{S}$ ). For each compound 1-3, we have computed at the RI-MP2/def2-TZVP level of theory ChB complexes using two possible binding modes, by pointing the electron donor to either $\sigma$-hole. We have used several Lewis bases and chloride anion as electron donors ( $\mathrm{ChB}$ acceptors) and we have compared their geometric and energetic features (see Scheme 1 for the whole set of complexes studied herein).

First of all, we have computed the MEP surfaces of compounds 1-3 (Fig. 3). From the inspection of the results, several interesting issues arise. First, for the morpholinosulfur trifluoride (1), the MEP values at both $\sigma$-holes are similar, being the one opposite to the $\mathrm{S}-\mathrm{F}$ bond slightly more positive. For the phenyl substituted compound (2), the $\sigma$-hole opposite to the $\mathrm{C}$ atom is $7.2 \mathrm{kcal} / \mathrm{mol}$ smaller than that opposite to the $\mathrm{F}$ atom, consistent with the different electronegativity of $\mathrm{C}$ and F. Finally, in case of compound 3, the $\sigma$-hole opposite to the $\mathrm{N}-\mathrm{S}$ bond is similar but unexpectedly more positive than that opposite to the F-S bond. Therefore in this compound we may anticipate that the ChB will be stronger when the electron rich atom is located opposite to the $\mathrm{N}-\mathrm{S}$ bond. It is also worth mentioning the MEP energy differences at the $\sigma$-hole opposite to the $\mathrm{F}-\mathrm{S}$ bond. That is, in compound $\mathbf{1}$ the MEP value $(+13.9$ $\mathrm{kcal} / \mathrm{mol})$ is significantly smaller compared to either $2(+18.4$ $\mathrm{kcal} / \mathrm{mol})$ or $3(+22.2 \mathrm{kcal} / \mathrm{mol})$. This is likely due to the fact that in $\mathbf{1}$ the lone pair at the $\mathrm{sp}^{3} \mathrm{~N}$ atom and the $\sigma$-hole oposite to $\mathrm{S}-\mathrm{F}$ are pointing to the same region. Therefore, there is a significant orbital overlap between the filled LP orbital at the $\mathrm{N}$ atom and the antibonding $\sigma^{*} \mathrm{~S}-\mathrm{F}$ orbital that has its maximum amplitude in the same location as the $\sigma$-hole, thus increasing electron density in the $\sigma$-hole.

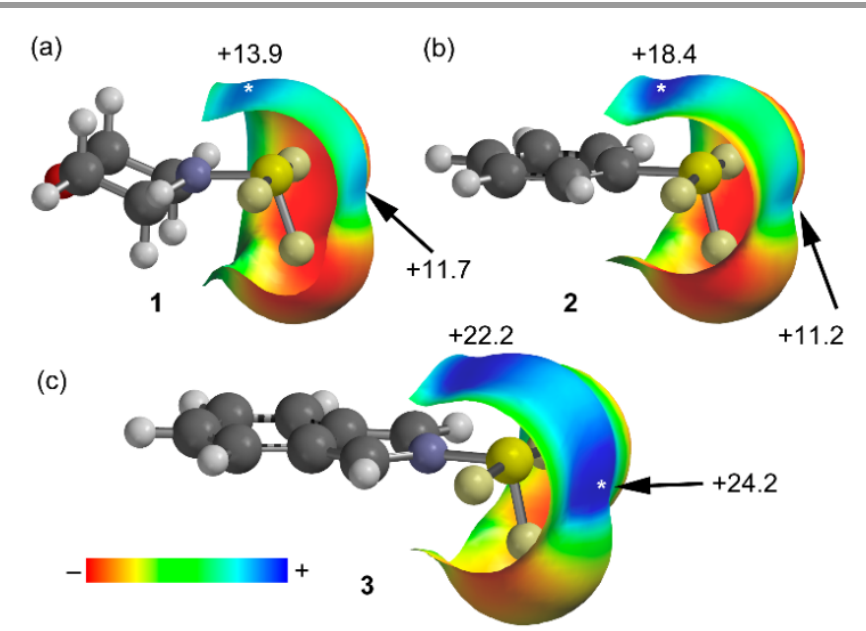

Fig. 3 MEP open surfaces of compounds 1 to 3 . Energies at selected points of the surface (0.001 a.u.) are given in $\mathrm{kcal} / \mathrm{mol}$. Maximum indicated with asterisk

$$
\begin{aligned}
& R, F_{1}, \quad \text { 1, } \mathrm{R}=4 \text {-morpholinyl Electron donors: }
\end{aligned}
$$

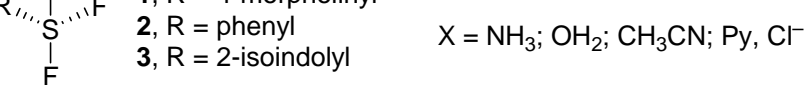

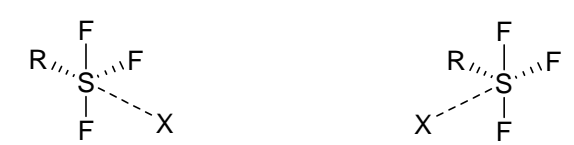

4a, $\mathrm{R}=4$-morpholinyl, $\mathrm{X}=\mathrm{OH}_{2}$

5a, $\mathrm{R}=4$-morpholinyl, $X=\mathrm{NH}_{3}$

6a, $R=4$-morpholinyl, $X=P y$

4b, $\mathrm{R}=4$-morpholinyl, $\mathrm{X}=\mathrm{OH}_{2}$

5b, $\mathrm{R}=4$-morpholinyl, $\mathrm{X}=\mathrm{NH}_{3}$

6b, $R=4$-morpholinyl, $X=P y$

7a, $\mathrm{R}=4$-morpholinyl, $\mathrm{X}=\mathrm{NCCH}_{3} \quad 7 \mathrm{~b}, \mathrm{R}=4$-morpholinyl, $\mathrm{X}=\mathrm{NCCH}_{3}$

8a, $\mathrm{R}=4$-morpholinyl, $\mathrm{X}=\mathrm{Cl}^{-}$

9a, $\mathrm{R}=$ phenyl, $\mathrm{X}=\mathrm{OH}_{2}$

10a, $\mathrm{R}=$ phenyl, $X=\mathrm{NH}_{3}$

11a, $R=$ phenyl, $X=P y$

12a, $\mathrm{R}=$ phenyl, $X=\mathrm{NCCH}_{3}$

13a, $\mathrm{R}=$ phenyl, $\mathrm{X}=\mathrm{Cl}^{-}$

14a, $\mathrm{R}=2$-isoindolyl, $X=\mathrm{OH}_{2}$

15a, $\mathrm{R}=2$-isoindolyl, $\mathrm{X}=\mathrm{NH}_{3}$

16a, $R=2$-isoindolyl, $X=P y$

17a, $\mathrm{R}=2$-isoindolyl, $\mathrm{X}=\mathrm{NCCH}_{3}$

18a, $\mathrm{R}=2$-isoindolyl, $\mathrm{X}=\mathrm{Cl}^{-}$

8b, $\mathrm{R}=4$-morpholinyl, $\mathrm{X}=\mathrm{Cl}^{-}$

9b, $\mathrm{R}=$ phenyl, $\mathrm{X}=\mathrm{OH}_{2}$

10b, $\mathrm{R}=$ phenyl, $X=\mathrm{NH}_{3}$

11b, $R=$ phenyl, $X=P y$

12b, $\mathrm{R}=$ phenyl, $X=\mathrm{NCCH}_{3}$

13b, $\mathrm{R}=$ phenyl, $\mathrm{X}=\mathrm{Cl}^{-}$

14b, $\mathrm{R}=2$-isoindolyl, $X=\mathrm{OH}_{2}$

15b, $\mathrm{R}=2$-isoindolyl, $X=\mathrm{NH}_{3}$

16b, $R=2$-isoindolyl, $X=P y$

17b, $\mathrm{R}=2$-isoindolyl, $\mathrm{X}=\mathrm{NCCH}_{3}$

18b, $\mathrm{R}=2$-isoindolyl, $\mathrm{X}=\mathrm{Cl}^{-}$

Scheme 1. Compounds and complexes $\mathbf{1}$ to 18 used in this study. 


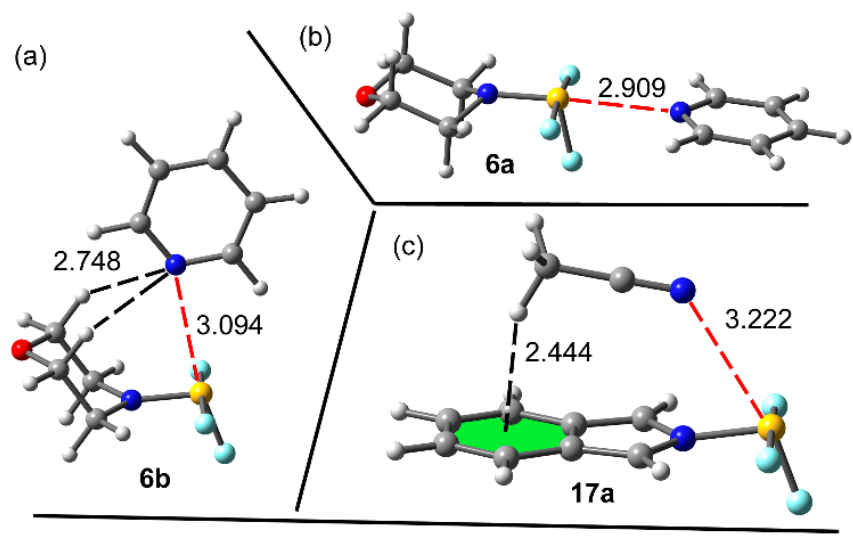

(d)

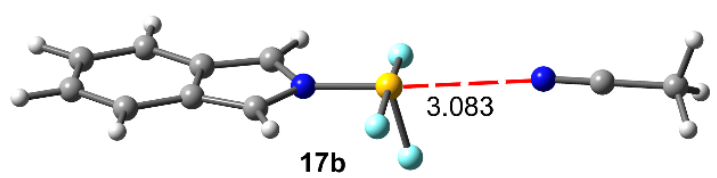

Fig. 4 Optimized geometries of some representative complexes at the RI-MP2/def2 TZVP level of theory. Ancillary interactions represented by black dashed lines. Chalcogen bonding interactions represented in red dashed lines

The LP of isoindolyl nitrogen is involved in the aromatic delocalization thus it is less prone to overlap with $\sigma^{*} \mathrm{~S}-\mathrm{F}$ orbital.

The interaction energy values (RI-MP2/def2-TZVP) for complexes 4-18 (see Scheme 1) are gathered in Table 2. The complexes of type $\mathrm{b}$ (opposite to $\mathrm{S}-\mathrm{F}$ bond) are systematically more stable [negative values of $\Delta \Delta \mathrm{E}(\mathrm{b}-\mathrm{a})$, see Table 2] than those of type a (opposite to $\mathrm{S}-\mathrm{N} / \mathrm{C}$ ), apart from complexes $\mathbf{1 8 a , b}$ as further discussed below. The energies for the neutral complexes are moderately strong, ranging from -8.2 to -1.3 $\mathrm{kcal} / \mathrm{mol}$. For the anionic complexes, the energies are stronger, ranging from -29.2 to $-9.4 \mathrm{kcal} / \mathrm{mol}$. It is interesting to highlight that the energy differences $\Delta \Delta \mathrm{E}(\mathrm{b}-\mathrm{a})$ are very small for the $\mathrm{R}=4$-morpholinyl complexes. In addition, for most of these complexes the equilibrium distance $(S \cdots X)$ is shorter when the electron donor is opposite to the $S-R$ bond. This fact is unexpected taking into consideration the electron withdrawing ability of $F$. In addition, a close examination of the geometries of the complexes type $b$ reveals that they exhibit ancillary interactions which contribute to the stabilization of the complex and which are not present in the complexes opposite to the N/C-S bond. In Fig. 4 we have represented some selected examples. In complex $\mathbf{6 a}$, the pyridine $\mathrm{N}$ atom interacts with the axial $\mathrm{C}-\mathrm{H}$ bonds of the morpholine ring, and these interactions further contribute to the binding energy of the adduct. In complex 17a, the methyl group of the donor molecule interacts with the $\pi$-system of the organic moiety. In contrast to complexes $\mathbf{5 b}$ and $\mathbf{1 8 b}$, the directionality of the ChB is ideal in $\mathbf{5 a}$ and $\mathbf{1 7} \mathbf{a}$, where the LP of the ChB acceptor points to the $\sigma$-hole opposite to the $S-R$ bond.

\begin{tabular}{|c|c|c|c|c|}
\hline Complex & $\Delta \mathrm{E}$ & $\Delta \Delta \mathrm{E}(\mathrm{b}-\mathrm{a})$ & $\mathrm{R}$ & $\angle \mathrm{C} / \mathrm{N}-\mathrm{S} \cdots \times\left({ }^{\circ}\right)$ \\
\hline $4 a\left(1+\mathrm{OH}_{2}\right)$ & -2.5 & & 3.363 & 170.6 \\
\hline $4 \mathrm{~b}\left(1+\mathrm{OH}_{2}\right)$ & -2.8 & -0.3 & 3.288 & 176.6 \\
\hline $5 \mathrm{a}\left(1+\mathrm{NH}_{3}\right)$ & -2.7 & & 3.059 & 175.2 \\
\hline $5 \mathbf{b}\left(1+\mathrm{NH}_{3}\right)$ & -3.0 & -0.3 & 3.331 & 172.3 \\
\hline $6 a(1+P y)$ & -4.1 & & 2.909 & 177.9 \\
\hline 6b $(1+P y)$ & -4.5 & -0.4 & 3.094 & 177.5 \\
\hline $\mathrm{7a}\left(1+\mathrm{NCCH}_{3}\right)$ & -1.3 & & 3.194 & 179.3 \\
\hline $7 \mathbf{b}\left(1+\mathrm{NCCH}_{3}\right)$ & $-5.0^{\mathrm{a}}$ & -3.7 & 3.771 & 172.4 \\
\hline $8 a\left(1+\mathrm{Cl}^{-}\right)$ & -9.4 & & 2.644 & 178.6 \\
\hline $8 b\left(1+\mathrm{Cl}^{-}\right)$ & -19.8 & -10.4 & 3.035 & 174.7 \\
\hline $9 a\left(2+\mathrm{OH}_{2}\right)$ & -2.6 & & 3.159 & 170.8 \\
\hline $9 \mathbf{b}\left(2+\mathrm{OH}_{2}\right)$ & -3.4 & -0.8 & 3.004 & 176.9 \\
\hline $10 \mathrm{a}\left(2+\mathrm{NH}_{3}\right)$ & -3.2 & & 2.992 & 174.7 \\
\hline $10 \mathbf{b}\left(2+\mathrm{NH}_{3}\right)$ & -4.8 & -1.6 & 2.940 & 176.4 \\
\hline 11a (2 + Py) & -4.8 & & 2.839 & 175.4 \\
\hline $11 b(2+P y)$ & -8.2 & -3.4 & 2.772 & 172.7 \\
\hline $12 \mathrm{a}\left(2+\mathrm{NCCH}_{3}\right)$ & -2.7 & & 3.356 & 178.2 \\
\hline $12 b\left(2+\mathrm{NCCH}_{3}\right)$ & -4.8 & -2.1 & 3.166 & 178.8 \\
\hline 13a $\left(2+\mathrm{Cl}^{-}\right)$ & -10.6 & & 2.640 & 176.3 \\
\hline $13 b\left(2+\mathrm{Cl}^{-}\right)$ & -22.1 & -11.5 & 2.492 & 172.6 \\
\hline $14 a\left(3+\mathrm{OH}_{2}\right)$ & -3.7 & & 2.905 & 177.7 \\
\hline $14 \mathbf{b}\left(3+\mathrm{OH}_{2}\right)$ & -5.8 & -2.1 & 3.580 & 161.9 \\
\hline $15 a\left(3+N_{3}\right)$ & -5.0 & & 2.855 & 176.1 \\
\hline $15 \mathbf{b}\left(3+\mathrm{NH}_{3}\right)$ & -6.6 & -1.6 & 2.944 & 173.6 \\
\hline $16 a(3+P y)$ & -6.8 & & 2.681 & 175.8 \\
\hline $16 b(3+P y)$ & -10.4 & -3.6 & 2.686 & 166.8 \\
\hline $17 a\left(3+\mathrm{NCCH}_{3}\right)$ & -3.1 & & 3.083 & 176.9 \\
\hline $17 b\left(3+\mathrm{NCCH}_{3}\right)$ & -9.3 & -6.2 & 3.222 & 168.0 \\
\hline $18 \mathrm{a}\left(3+\mathrm{Cl}^{-}\right)$ & -29.2 & & 2.340 & 174.1 \\
\hline $18 \mathrm{~b}\left(3+\mathrm{Cl}^{-}\right)$ & -29.0 & +0.2 & 2.398 & 173.3 \\
\hline
\end{tabular}

For the anionic complexes, it is interesting to note the different behavior of phenyl and 2-isoindolyl substituted compounds. For the former, the type $b$ chalcogen bonded complex (13b) is significantly more favored than type a (13a), in agreement with the MEP surface analysis. For the latter, the type a chalcogen bonded complex (18a) is slightly more favored than type $b(\mathbf{1 8 b})$ once again in agreement with the MEP analysis. It is worthy to comment that complexes 18a and $\mathbf{1 8 b}$ do not present ancillary interactions and consequently the energetic and geometric results demonstrate that the $\mathrm{ChB}$ can be more favored opposite to a highly polarizable group than opposite to a strong electron withdrawing atom.

We have also performed the Bader's "atoms-in-molecules" analysis of the morpholine complexes in order to characterize the interactions and also compare the electron density at the bond critical point that characterizes the $\mathrm{ChB}$. It is well known that the charge density at the bond $\mathrm{CP}$ is a good indication of the strength of the interaction. The distribution of critical points and bond paths for complexes $\mathbf{4 - 8}$ is given in Figs. 5 and S1. Fig. 5 shows that the chalcogen bonded complexes $4 \mathbf{a}$, 5a and $\mathbf{8 a}$ are characterized by only one bond critical point (green sphere) and bond path that interconnect the electron donor 
atom and the sulfur atom. However, in complexes $\mathbf{4 a}, \mathbf{5 b}$ and $\mathbf{8 b}$, the distribution is more complicated and the electron donor atom is connected to $\mathbf{1}$ by means of three bond critical points and bond paths. Two of them are symmetrically distributed and connect the electron rich atom to both axial $\mathrm{H}$ atoms of the morpholine ring. The third bond critical point connects the sulfur atom to the lone pair donor atom or anion, thus characterizing the $\mathrm{ChB}$. (a)

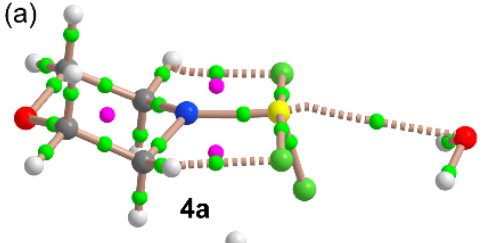

(c)

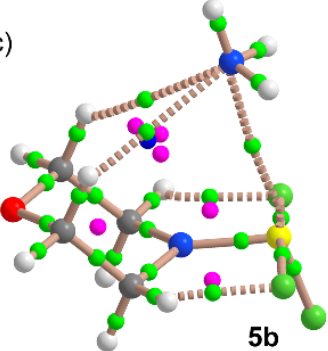

(e)

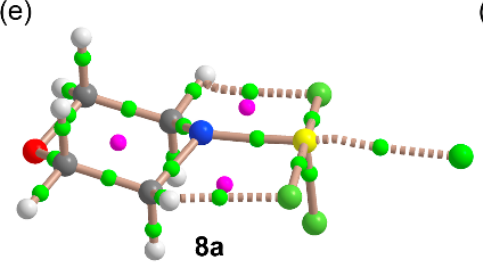

(b)

(d)

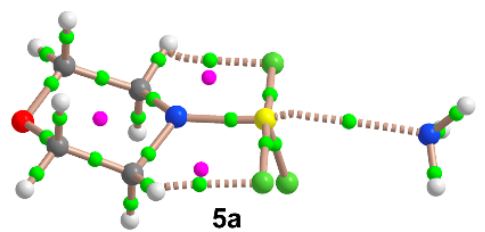

(f)

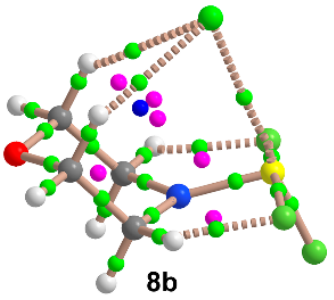

Fig. 5 (a-f) Distribution of bond, ring and cage critical points (green, pink and blue spheres, respectively) and bond paths for types a and b of complexes $\mathbf{4}, \mathbf{5}$ and $\mathbf{8}$ at the MP2/def2-TZVP.

In Table 3 we gather the values of the charge density $[\rho(r)]$ and its Laplacian $\left[\nabla^{2} \rho(r)\right]$ at the bond $C P$ that characterizes the ChB for complexes 4-8. Quite remarkably, apart from the water complexes $\mathbf{4 a}$ and $\mathbf{4 b}$ where the values are similar, the rest of complexes present larger values of $\rho(r)$ and $\nabla^{2} \rho(r)$ when the electron rich atom is located opposite to the $\mathrm{N}-\mathrm{S}$ bond, thus suggesting a stronger $\mathrm{ChB}$. This is further confirmed by the natural bond order (NBO) analysis that is also included in Table 3. The NBO tool is adequate for studying orbital effects in $\sigma$ hole interactions. In fact, it has been recently used to analyze multivalent pnicogen, chalcogen, and halogen bonding interactions. $^{45}$ We have focused on the second order perturbation analysis to evaluate donor-acceptor interactions. The results summarized in Table 3 show that, apart from the water complexes, the $E^{(2)}$ energies are significantly larger in the type a chalcogen bonded complexes than in type $b$, in good agreement with the AIM analysis. Interestingly, there is a strong linear correlation between the $\rho(r)$ values at the bond critical point versus the $E^{(2)}$ energies $\left[\mathrm{LP} \rightarrow \sigma^{*}(\mathrm{~N} / \mathrm{F}-\mathrm{S})\right]$ with a regression coefficient $r=0.9903$. Thus both $\mathrm{NBO}$ and AIM verify that the $\mathrm{ChB}$ is stronger opposite to the organic substituents in most of the complexes.
Table 3. Electron charge density $[\rho(r)$, a.u. $]$ and Laplacian $\left[\nabla^{2} \rho(r)\right.$, a.u.] at the bond critical point that connects the $S$ atom to the electron rich atom in complexes 4-8. Second order perturbation energy $E^{(2)}(\mathrm{kcal} / \mathrm{mol})$ assigned to the $\mathrm{LP} \rightarrow \sigma^{*}$ donoracceptor orbital interaction in complexes 4-8.

\begin{tabular}{|c|c|c|c|}
\hline Complex & $\rho(r)$ & $\nabla^{2} \rho(r)$ & $\mathrm{LP} \rightarrow \sigma^{*}(\mathrm{~N} / \mathrm{F}-\mathrm{S})$ \\
\hline $4 a\left(1+\mathrm{OH}_{2}\right)$ & 0.0054 & 0.0225 & 0.26 \\
\hline $4 \mathbf{b}\left(1+\mathrm{OH}_{2}\right)$ & 0.0068 & 0.0265 & 0.35 \\
\hline $5 a\left(1+\mathrm{NH}_{3}\right)$ & 0.0128 & 0.0418 & 1.56 \\
\hline $5 b\left(1+N_{3}\right)$ & 0.0062 & 0.0249 & 0.17 \\
\hline $6 a(1+P y)$ & 0.0172 & 0.0557 & 2.15 \\
\hline $6 b(1+P y)$ & 0.0084 & 0.0277 & 0.42 \\
\hline $7 a\left(1+\mathrm{NCCH}_{3}\right)$ & 0.0082 & 0.0324 & 0.42 \\
\hline $7 \mathbf{b}\left(1+\mathrm{NCCH}_{3}\right)$ & $-^{\mathrm{a}}$ & $-^{a}$ & - \\
\hline $8 a\left(1+\mathrm{Cl}^{-}\right)$ & 0.0469 & 0.0765 & 12.2 \\
\hline $8 b\left(1+\mathrm{Cl}^{-}\right)$ & 0.0208 & 0.0542 & 5.13 \\
\hline
\end{tabular}

${ }^{\text {a }}$ No $\mathrm{S}$...N bond critical point found, see Fig. S1

As explained above, all chalcogen bonded complexes of $\mathbf{1}$ where the electron rich atom is oriented toward the $\sigma$-hole opposite to the F-S bond (type b) establish additional interactions and make it difficult a direct energetic and geometric comparison with type a complexes. To further analyze this issue, we have used an additional model of morpholine where the axial $\mathrm{H}$-atoms have been replaced by fluorine atoms (see Fig. 6). We have computed the complexes with chloride, because it showed the largest energy difference between both orientations ( $10.4 \mathrm{kcal} / \mathrm{mol}$, see Table 2). As shown in Fig. 6b, upon substitution of both Hs by fluorine atoms the complex opposite to the $\mathrm{F}-\mathrm{S}$ bond shows a highly directional $\mathrm{S} \cdots \mathrm{Cl}$ chalcogen bond without additional interactions and, consequently, a direct comparison is possible. Remarkably, the energy difference between both orientations is drastically reduced to $1.3 \mathrm{kcal} / \mathrm{mol}$, thus suggesting that both $\sigma$-holes have a similar ability to interact with Lewis bases. Therefore in the solid state, crystal packing effects can easily compensate the energy difference between the two possible orientations. These results are nicely consistent with the X-ray structures wherein unexpected ChBs opposite to the organic substituent instead of the most electron withdrawing F group are observed.

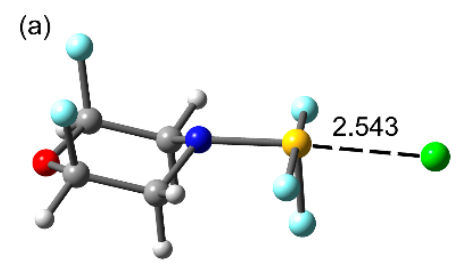

$\Delta \mathrm{E}=-14.1 \mathrm{kcal} \cdot \mathrm{mol}^{-1}$

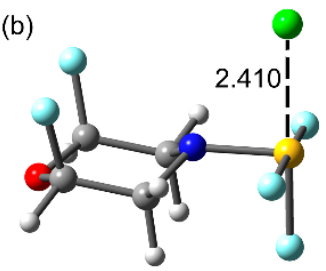

$\Delta \mathrm{E}=-15.4 \mathrm{kcal} \cdot \mathrm{mol}^{-1}$
Fig. $6 \mathrm{MP2} /$ def2-TZVP geometries and interaction energies of difluoride substituted morpholine sulfur trifluoride

\section{Conclusions}

In conclusion, we have provided theoretical (RI-MP2/def2TZVP level of theory) and experimental evidence (X-ray crystal structure analysis) of the existence of unexpected ChBs in 
crystalline structures where the electron rich atom points to the $\sigma$-hole opposite to the $\mathrm{R}-\mathrm{S}$ ( $\mathrm{R}=\mathrm{C}$ and $\mathrm{N}$ atoms) instead of the $\mathrm{F}-\mathrm{S}$ bond. When using a highly polarizable group at sulfur like 2-isoindolyl and a chloride anion as $\mathrm{ChB}$ acceptor, the $\mathrm{ChB}$ opposite to the $\mathrm{N}-\mathrm{S}$ bond is more favorable than that opposite to the $\mathrm{F}-\mathrm{S}$ bond. We believe that these results may function as useful heuristic principles of ChBs in crystal engineering and supramolecular chemistry where these interactions are increasingly recognized as functionally relevant.

Morpholinosulfur trifluoride (1) and analogous aminosulfuranes are common reagents used for fluorine for oxygen substitution in alcohols and ketones. These reactions proceed through the nucleophilic attack of oxygen on sulfur to give alkoxy-aminosulfurane intermediates. Results described in this paper give new insight of this attack and may thus help in optimizing these fluorination reactions.

\section{Theoretical Methods}

The energies of all complexes included in this study were computed at the RI-MP2/def2-TZVP level of theory. The geometries have been fully optimized imposing $C_{\mathrm{s}}$ symmetry constraints by using the program TURBOMOLE. ${ }^{45}$ All complexes and monomer are true minima, as confirmed by frequency analysis. The interaction energy (or binding energy in this work) $\Delta \mathrm{E}$, is defined as the energy difference between the optimized complex and the sum of the energies of the optimized monomers. For the calculations we have used the Weigend def2-TZVP ${ }^{46,47}$ basis set and the $\mathrm{MP}^{48} a b$ initio method. The MEP (Molecular Electrostatic Potential) calculations have been carried out by means of the SPARTAN software at the M06/6-31+G** level of theory. ${ }^{49}$ The AIM formalism elucidated bond paths via analysis of the topology of the electron density, ${ }^{50,51}$ making use of the AIMALL program. ${ }^{52}$ Charge transfer effects were assessed by the Natural Bond Orbital (NBO) methodology. ${ }^{53}$

\section{Conflicts of interest}

The authors have no conflict of interest to declare

\section{Acknowledgements}

We thank the MINECO/AEI (projects CTQ2017-85821-R, FEDER funds) for financial support. We thank the CTI (UIB) for computational facilities. A. F. thanks MINECO/AEI from SPAIN for a "Juan de la Cierva" contract

\section{Notes and references}

1 H. J. Schneider, Angew. Chem. Int. Ed., 2009, 48, 3924-3977.

2 J. M. Lehn in Supramolecular chemistry concepts and perspectives, Wiley-VCH, Weinheim, 1995.

3 J. W. Steed, J. L. Atwood in Supramolecular chemistry, Wiley, Chichester, 2000.

4 G. Gilli and P. Gilli, The Nature of the Hydrogen Bond, Oxford University Press, Oxford, 2009.
5 G. R. Desiraju and T. Steiner, The Weak Hydrogen Bond in Structural Chemistry and Biology, Oxford, New York, 1999.

6 S. Scheiner, Hydrogen Bonding. A Theoretical Perspective, Oxford University Press, New York, 1997.

7 S. J. Grabowski in Hydrogen Bonding-New Insights, Springer, Amsterdam, 2006.

8 G. Cavallo, P. Metrangolo, R. Milani, T. Pilati, A. Priimagi, G. Resnati and G. Terraneo, Chem. Rev., 2016, 116, 2478-2601

9 I. Alkorta, S. Rozas and J. Elguero, J. Phys. Chem. A, 1998, 102, 9278-9285.

10 A. Karpfen, J. Phys. Chem. A, 2000, 104, 6871-6879.

11 W. Zierkiewicz, R. Wieczorek, P. Hobza and D. Michalska, Phys. Chem. Chem. Phys., 2011, 13, 5105-5113.

12 K. E. Riley, C. L. Ford Jr. and K. Demouchet, Chem. Phys. Lett., 2015, 621, 165-170.

13 (a) P. Politzer, J. S. Murray in A unified view of halogen bonding, hydrogen bonding and other $\sigma$-hole interactions, Vol. 19 (Ed.: S. Scheiner), Springer, Dordrecht, 2015, pp. 357389; (b) J. S. Murray, P. Lane, T. Clark, K. E. Riley and P. Politzer, J. Mol. Model., 2012, 18, 541-548.

14 (a) S. Scheiner, Chem. Phys., 2011, 387, 79-84; (b) U. Adhikari and S. Scheiner, J. Phys. Chem. A, 2014, 118, 31833192.

15 W. Zierkiewicz, D. C. Bienko, D. Michalska and T. ZeegersHuyskens, J. Comput. Chem., 2015, 36, 821-832.

16 (a) S. A. Southern and D. L. Bryce, J. Phys. Chem. A, 2015, 119, 11891-11899; (b) S. A. Southern, D. Errulat, J. M. Frost, B. Gabidullin and D. L. Bryce, Faraday Discuss., 2017, 203, 165-186.

17 (a) A. Bauzá, T. J. Mooibroek and A. Frontera, Angew. Chem. Int. Ed., 2013, 52, 12317-12321; (b) A. Bauzá and A. Frontera, Angew. Chem. Int. Ed., 2015, 54, 7340-7343; (c) A. Bauzá, T. J. Mooibroek and A. Frontera, Chem. Commun., 2015, 51, 1491-1493.

18 J. E. Del Bene, I. Alkorta and J. Elguero in The pnicogen bond in review: Structures, energies, bonding properties, and spinspin coupling constants of complexes stabilized by pnicogen bonds, Vol. 19 (Ed.: S. Scheiner), Springer, Dordrecht, 2015, pp. 191-263.

19 Z. Latajka and S. Scheiner, J. Chem. Phys., 1987, 87, 11941204.

20 G. Sánchez-Sanz, C. Trujillo, I. Alkorta and J. Elguero, Phys. Chem. Chem. Phys., 2016, 18, 9148-9160.

21 S. J. Grabowski, Phys. Chem. Chem. Phys., 2014, 16, 18241834.

22 I. Alkorta, I. Rozas and J. Elguero, J. Phys. Chem. A, 2001, 105, 743-749.

23 S. Scheiner, CrystEngComm, 2013, 15, 3119-3124.

24 M. Marín-Luna, I. Alkorta and J. Elguero, Theor. Chem. Acc., 2017, 136, 41.

25 M. Liu, Q. Li and S. Scheiner, Phys. Chem. Chem. Phys., 2017, 19, 5550-5559.

26 B. R. Beno, K.-S. Yeung, M. D. Bartberger, L. D. Pennington, N. A. Meanwell, J. Med. Chem. 2015, 58, 4383-4438.

27 A. Bauzá, T. J. Mooibroek and A. Frontera, ChemPhysChem, 2015, 16, 2496-2517.

28 (a) A. Kremer, A. Fermi, N. Biot, J. Wouters and D. Bonifazi, Chem. Eur. J., 2016, 22, 5665-5675; (b) P. C. Ho, P. Szydlowski, J. Sinclair, P. J. W. Elder, J. Kubel, C. Gendy, L. M. Lee, H. Jenkins, J. F. Britten, D. R. Morim and I. Vargas-Baca, Nat. Commun., 2016, 7, 11299; (c) G. E. Garrett, E. I. Carrera, D. S. Seferos and M. S. Taylor, Chem. Commun., 2016, 52, 9881-9884; (d) N. A. Semenov, A. V. Lonchakov, N. A. Pushkarevsky, E. A. Suturina, V. V. Korolev, E. Lork, V. G. Vasiliev, S. N. Konchenko, J. Beckmann, N. P. Gritsan and A. V. Zibarev, Organometallics, 2014, 33, 4302-4314.

29 S. Benz, M. Macchione, Q. Verolet, J. Mareda, N. Sakai and S. Matile, J. Am. Chem. Soc., 2016, 138, 9093-9096. 
30 (a) V. B. Birman and X. Li, Org. Lett., 2006, 8, 1351-1354; (b) S. Fukumoto, T. Nakashima and T. Kawai, Angew. Chem. Int Ed., 2011, 50, 1565-1568; (c) C. A. Leverett, V. C. Purohit and D. Romo, Angew. Chem. Int. Ed., 2010, 49, 9479-9483; (d) E. R. T. Robinson, D. M. Walden, C. Fallan, M. D. Greenhalgh, P. H.-Y. Cheong and A. D. Smith, Chem. Sci., 2016, 7, 69196927.

31 (a) M. E. Cinar and T. Ozturk, Chem. Rev., 2015, 115, 30363140; (b) G. Barbarella and F. Di Maria, Acc. Chem. Res., 2015, 48, 2230-2241.

32 A. Kremer, A. Fermi, N. Biot, J. Wouters, D. Bonifazi, Chem. Eur. J., 2016, 22, 5665-5675.

33 P. Wonner, L. Vogel, M. Düser, L. Gomes, F. Kniep, B. Mallick, D. B. Werz and S. M. Huber, Angew. Chem. Int. Ed., 2017, 56 12009-12012.

34 S. Benz, J. Mareda, C. Besnard, N. Sakai and S. Matile, Chem. Sci., 2017, 8, 8164-8169.

35 S. Benz, C. Besnard and S. Matile, Helv. Chim. Acta, 2018, 101, e1800075.

36 J. Y. C. Lim, I. Marques, A. L. Thompson, K. E. Christensen, V. Félix and P. D. Beer, J. Am. Chem. Soc., 2017, 139, 3122-3133

37 D. J. Pascoe, K. B. Ling, and S. L. Cockroft, J. Am. Chem. Soc. 2017, 139, 15160-15167.

38 O. Jeannin, H.-T. Huynh, A. M. S. Riela and M. Fourmigué, New J. Chem., 2018, 42, 10502-10509.

39 (a) A. Bauzá, D. Quiñonero, P. M. Deyà and A. Frontera, CrystEngComm, 2013, 15, 3137-3144; (b) M. Iwaoka and N. Isozumi, Molecules, 2012, 17, 7266-7283; (c) G. SánchezSanz, C. Trujillo, I. Alkorta and J. Elguero, ChemPhysChem. 2012, 13, 496-503; (d) P. Sanz, O. Mó and M. Yáñez, Phys. Chem. Chem. Phys., 2003, 5, 2942-2947; (e) M. H. Esseffar, R. Herrero, E. Quintanilla, J. Z. Dávalos, P. Jiménez, J.-L. M. Abboud, M. Yáñez and O. Mó, Chem. Eur. J., 2007, 13, 17961803.

40 U. Adhikari and S. Scheiner, Chem. Phys. Lett., 2011, 514, 3639.

41 (a) V. de P. N. Nziko and S. Scheiner, J. Phys. Chem. A, 2014 118, 10849-10856; (b) P. Chaudhary, J. T. Goettel, H. P. A Mercier, S. Sowlati-Hashjin, P. Hazendonk, M. Gerken, Chem.-Eur.J., 2015, 21, 6247 6256; (c) J. T. Goettel, P. Chaudhary, P. Hazendonk, H. P. A. Mercier and M. Gerken, Chem. Commun., 2012, 48, 9120-9122; (d) J. T. Goettel and M. Gerken, Inorg. Chem., 2016, 55, 12441-12450; (e) P. Politzer, J. S. Murray, T. Clark and G. Resnati, Phys. Chem. Chem. Phys., 2017, 19, 32166-32178.

42 S. Scheiner and J. Lu, Chem. Eur. J., 2018, 24, 8167-8177.

43 (a) R. Surmont, G. Verniest, A. De Groot, J. W. Thuring and N. De Kimpe, Adv. Syn. Cat., 2010, 352, 2751-2756; (b) R. Surmont, G. Verniest, A. De Weweire, J. W. Thuring, G. Macdonald, F. Deroose and N. de Kimpe, Synlett, 2009, 12, 1933-1936; (c) A. Franconetti, Synlett, 2013, 24, 891-892

44 (a) P.A. Messina, K. C. Mange and W. J. Middleton, J. Fluorine Chem., 1989, 42, 137-143; (b) A. Franconetti, S. Jatunov, P. Borrachero, M. Gómez-Guillén and F. Cabrera-Escribano, Org. Biomol. Chem., 2013, 11, 676-686; (c) A. Franconetti, P Borrachero, M. Gómez-Guillén and F. Cabrera-Escribano, Synlett, 2013, 24, 249-253.

45 R. Ahlrichs, M. Bär, M. Hacer, H. Horn and C. Kömel, Chem. Phys. Lett., 1989, 162, 165-169.

46 F. Weigend and R. Ahlrichs, Phys. Chem. Chem. Phys., 2005, 7, 3297-3305.

47 F. Weigend, Phys. Chem. Chem. Phys., 2006, 8, 1057-1065

48 M. J. Frisch, M. Head-Gordon and J. A. Pople, Chem. Phys. Lett., 1990, 166, 275-280

49 Y. Shao, L.F. Molnar, Y. Jung, J. Kussmann, C. Ochsenfeld, S.T. Brown, A.T.B. Gilbert, L.V. Slipchenko, S.V. Levchenko, D.P. O'Neill, R.A. DiStasio Jr., R.C. Lochan, T. Wang, G.J.O. Beran, N.A. Besley, J.M. Herbert, C.Y. Lin, T. Van Voorhis, S.H. Chien,
A. Sodt, R.P. Steele, V.A. Rassolov, P.E. Maslen, P.P. Korambath, R.D. Adamson, B. Austin, J. Baker, E.F.C. Byrd, H. Dachsel, R.J. Doerksen, A. Dreuw, B.D. Dunietz, A.D. Dutoi, T.R. Furlani, S.R. Gwaltney, A. Heyden, S. Hirata, C-P. Hsu, G. Kedziora, R.Z. Khalliulin, P. Klunzinger, A.M. Lee, M.S. Lee, W.Z. Liang, I. Lotan, N. Nair, B. Peters, E.I. Proynov, P.A. Pieniazek, Y.M. Rhee, J. Ritchie, E. Rosta, C.D. Sherrill, A.C. Simmonett, J.E. Subotnik, H.L. Woodcock III, W. Zhang, A.T. Bell, A.K. Chakraborty, D.M. Chipman, F.J. Keil, A.Warshel, W.J. Hehre, H.F. Schaefer, J. Kong, A.I. Krylov, P.M.W. Gill and M. Head-Gordon, Phys. Chem. Chem. Phys., 2006, 8, 3172-3191.

50 R. F. W. Bader, M. T. Carroll, J. R. Cheeseman and C. Chang, J. Am. Chem. Soc., 1987, 109, 7968-7979.

51 R. F. W. Bader, Atoms in Molecules, A Quantum Theory, Clarendon, Oxford, 1990.

52 AIMAll (Version 17.11.14), T. A. Keith, TK Gristmill Software, Overland Park KS, USA, (aim.tkgristmill.com), 2013.

53 E. D. Glendening, C. R. Landis and F. Weinhold, J. Comput. Chem., 2013, 34, 1429-1437. 